\title{
PREVALENCE OF DIABETIC RETINOPATHY IN PATIENTS WITH TYPE 1 DIABETES MELLITUS
}

Jorge F. Esteves ${ }^{1}$, Caroline K. Kramer ${ }^{2}$, Mirela Jobim de Azevedo ${ }^{3}$, Andressa P. Stolz ${ }^{4}$, Murilo F. Roggia ${ }^{4}$, Andréia Larangeira 5 , Suellen A. Miozzo 5 , Carolina Rosa ${ }^{5}$, Jose Humberto Lambert ${ }^{5}$, Miriam Pecis ${ }^{6}$, Ticiana C. Rodrigues ${ }^{7}$, Luis Henrique Santos Canani ${ }^{* 8}$

Trabalho realizado no Serviço de Oftalmologia, Hospital de Clínicas de Porto Alegre, Porto Alegre, Brasil, Serviço de Endocrinologia, Hospital de Clínicas de Porto Alegre, Porto Alegre, Brasil Universidade Federal do Rio Grande do Sul, Porto Alegre, RS

\author{
*Correspondência: \\ Serviço de Endocrinologia \\ do Hospital de Clínicas de \\ Porto Alegre \\ Ramiro Barcelos 2350, \\ Prédio $12,4^{\circ}$ andar, \\ CEP: 90035-003, \\ Porto Alegre, RS, Brasil. \\ Fone: 5121018127 \\ Fax: 555121018777 \\ luiscanani@yahoo.com
}

\begin{abstract}
SUMMARY
Prevalence of diabetic retinopathy in patients with type 1 diabetes mellitus

OвJEctives. Diabetic retinopathy (DR) is the leading cause of legal blindness in young adults. Scarce data from Brazilian subjects with type 1 diabetes mellitus (DM) are available. Aims: The objectives of this study were to determine the prevalence of DR and its risk factors in type 1 diabetes mellitus (DM) outpatients from a general hospital.

Methods. A cross-sectional study of 437 type 1 DM (50.3\% males, $82.4 \%$ whites) was conducted. DR was graded as absent, mild and moderate non-proliferative DR (mild/moderate NPDR) or severe non-proliferative and proliferative DR (advanced DR). Presence of clinically significant macular edema (CSME) was also recorded.

Results. Any DR was present in $44.4 \%$ of subjects. In multivariate analysis, DM duration, systolic blood pressure (SBP) and A1C test were associated with mild/moderate NPDR $(P<0.005)$. Advanced $\mathrm{DR}$, was associated with DM duration, SBP, smoking [odds ratio (OR) 2.75, 95\% Cl 1.15-6.60] and micro-or macroalbuminuria (OR 8.53, 95\% Cl 3.81-18.05). CSME was present in 21 (9.4\%) patients and was associated with smoking $(\mathrm{OR} 3.19,95 \% \mathrm{Cl} 1.24-8.2)$. Its frequency increased with the severity of DR $(16.4 \%$ in advanced DR, $9.6 \%$ in mild/moderate NPDR, and $4.7 \%$ in the group without $D R ; P=0.020$ ).

Conclusion. Patients with type 1 DM attending an endocrine out-patient clinic at a general hospital had a high prevalence of DR associated with traditional risk-factors and smoking.
\end{abstract}

KEY wORDS: Type 1 diabetes mellitus. Diabetic retinopathy. Risk factors.

\section{INTRODUCTION}

Diabetic retinopathy (DR) is the most frequent microvascular complication of diabetes mellitus (DM), resulting in blindness for over 10,000 people with DM every year ${ }^{1}$ and is the leading cause of legal blindness ${ }^{2}$. In type $1 \mathrm{DM}$, the overall prevalence of DR after eleven years of follow-up is $66.6 \%^{3}$, and almost all patients have some degree of DR after 20 years of DM 4,5 . Further, severe forms of the disease leading to visual impairment occur in $50 \%$ of type 1 DM patients ${ }^{2}$.

The main risk factors for the development and progress of DR are persistent hyperglycemia, DM duration and high blood pressure levels $\mathrm{s}^{6-11}$. However, there is an important individual variability in incidence of DR among diabetic patients. The question often asked is why some patients under good metabolic control develop DR while others remain free of this complication, despite poorly controlled $\mathrm{DM}^{12}$. This may be due to different genetic backgrounds.

The aims of the present study were to describe prevalence of DR and its risk factors in type 1 DM outpatients from a general hospital in Southern Brazil.

\section{Methods}

\section{Research design}

This is a cross-sectional study that described baseline characteristics of a prospective cohort study of outpatients with type 1 DM from July 2003 to December 2007.

1. Professor assistente do Departamento de Oftalmologia da Universidade Federal do Rio Grande do Sul, Porto Alegre, RS

2. Aluna de doutorado do Programa de Pós Graduação Ciências Médicas: Endocrinologia da Universidade Federal do Rio Grande do Sul, Porto Alegre, RS

3. Professora adjunta do Departamento de Medicina Interna da Universidade Federal do Rio Grande do Sul, Porto Alegre, RS

4. Médica residente do Serviço de Oftalmologia do Hospital de Clinicas de Porto Alegre, Porto Alegre, RS

5. Estudante de medicina - Estudante de Medicina da Universidade Federal do Rio Grande do Sul, Porto Alegre, RS

6. Bolsista de Pós-doutorado do CNPq

7. Médica do Serviço de Endocrinologia do Hospital de Clínicas de Porto Alegre, Porto Alegre, RS

8. Professor adjunto do Departamento de Medicina Interna da Universidade Federal do Rio Grande do Sul, Porto Alegre, RS 


\section{Subjects}

Patients with type 1 DM attending the Hospital de Clínicas de Porto Alegre, Brazil, in the Endocrine Clinic and referred to the Ophthalmology Clinic for routine eye examination were included. The criteria for referral were patients more than 18 years of age with a diagnosis of type $1 \mathrm{DM}$ for five years or more. Definition of type $1 \mathrm{DM}$ was based on the presence of DM, diagnosed before 30 years of age, at least one episode of diabetic cetoacidosis and/or cetonemia and need for insulin therapy within 1 year of DM diagnosis ${ }^{13}$.

\section{Eye examination and classification of retinopathy}

Eye examination included, in addition to fundoscopy, visual acuity test (logMAR notation), refraction, tonometry and biomicroscopy of the anterior segment.

DR was graded at the time of ophthalmologic assessment by fundoscopy through dilated pupils by the same researcher (JFE) and severity was established using the scale developed by the Global Diabetic Retinopathy Group ${ }^{14}$. The first level was "absent DR", with no fundus abnormalities; the second was "mild non proliferative diabetic retinopathy (NPDR)", microaneurysms only; the third, "moderate NPDR", included more than just microaneurysms, but less than severe NPDR; the fourth, "severe NPDR", included any of the following: $>20$ intra-retinal hemorrhages in each of the 4 quadrants, definite venous beading in $2+$ quadrants, prominent intra-retinal microvascular abnormalities in $1+$ quadrant, and no signs of proliferative DR; and the fifth level, "proliferative DR" (PDR), which includes eyes with one or more of the following: definite neovascularization or vitreous/ pre-retinal hemorrhage ${ }^{15}$.

Classification of patient DR was based on the most severe degree of retinopathy in the worst affected eye. We have previously described an excellent agreement of DR classification $(95.3 \%$ ) carried out by different trained ophthalmologists from our group ${ }^{16}$. Therefore, in the present study only a single observer, not aware of the patients' clinical data, classified all the subjects

According to the DR classification, three groups were defined for further analysis: 1 - absent DR; 2 - mild and moderate NPDR (mild/moderate NPDR) and 3- severe non proliferative and proliferative DR (advanced DR group).

Macular edema was evaluated upon dilated eyes, using slitlamp biomicroscopy in a subset of patients. Clinically significant macular edema (CSME) was defined as one or more of the following: any retinal thickening within $500 \mathrm{~mm}$ of the center of the macula, with or without loss of retinal transparency; hard exudates associated with retinal thickening within $500 \mathrm{~mm}$ of the center of the macula; or one disc area of thickening within one disc diameter of the center of the macula ${ }^{17,18}$.

\section{Clinical evaluation}

Risk factors for DR were recorded at the time of ophthalmologic examination and included age, age at onset of DM, DM duration, ethnicity (self reported), smoking habit, body mass index (BMI), systolic blood pressure (SBP) and diastolic blood pressure (DBP). All patients answered a brief standard questionnaire and underwent physical examination and laboratory tests. They were weighed wearing light outdoor clothes without shoes and height was recorded. BMI was calculated as weight (kilograms)/height ${ }^{2}$ (meters). Waist circumference was measured on a horizontal plane, midway between the inferior margin of the ribs and the superior border of the iliac crest. Sitting blood pressure was measured twice on the right arm to the nearest $2 \mathrm{~mm} \mathrm{Hg}$ after a 10 minute rest using a standard mercury sphygmomanometer (phases I and $V$ of Korotkoff sounds). Subjects who smoked one or more cigarettes daily were classified as current smokers. Those who had smoked in the past and stopped for more than one year were classified as former smokers.

\section{Laboratory methods}

Laboratory evaluations consisted of measuring A1C test, lipid profile, serum creatinine and urinary albumin excretion (UAE). FPG was determined by enzymatic colorimetric assay (through glucose oxidase enzyme). A1C test was measured by highperformance liquid chromatography system (reference range 4.7 - 6.0\%; Merck-Hitachi 9100, Merck, Darmstadt, Germany). Fasting plasma glucose was measured by the glucose-peroxidase colorimetric enzymatic method (Biodiagnostica). Creatinine was measured by the Jaffé method and serum total cholesterol, triglycerides were measured by enzymatic-colorimetric methods (Merck Diagnostica, Darmstadt, Germany; Boeringher Mannheim, Buenos Aires, Argentina) and HDL cholesterol was measured by homogeneous direct method (autoanalyzer, ADVIA 1650). LDL cholesterol was calculated using the Friedewald formula. Albuminuria was measured in a sterile spot urine sample by turbidimetric immunoassay on at least two occasions in patients without end-stage renal disease (ESRD); values below $17 \mathrm{mg} / \mathrm{l}$ were considered as normoalbuminúria ( $\mathrm{n}$ $=190)$, between 17-174 mg/l microalbuminuria $(n=56)$ and $>174 \mathrm{mg} / \mathrm{dl}$, as macroalbuminuria $(n=33)$ [19]. Patients with ESRD ( $n=10$, dialysis) were included in the macroalbuminuric group. Glomerular filtration rate (GFR) was estimated using the Modification of Diet in Renal Disease (MDRD) formula: $186 \mathrm{x}$ [plasma creatinine $(\mathrm{mg} / \mathrm{dl})^{-1.154} \mathrm{x}$ age $(\mathrm{yr})^{-0.203} \times(1.212$ if black) $x(0.742$ if female)][20].

The study protocol was approved by the Hospital Ethics Committees and an informed consent was obtained from all patients.

\section{Statistical analysis}

In univariate analysis the Chi-square test and the one-way analysis of variance (ANOVA) followed by post-hoc Bonferroni test on residual analyses were used. Multinomial multivariate regression was performed with $\mathrm{DR}$ as the dependent variable (absent DR, mild/moderate NPDR and advanced DR, and all variables associated with the presence of $D R$ in the univariate analysis were included as independent variables. $P$ value $<0.05$ was considered significant. Continuous variables were presented as mean \pm standard deviation. Variables with a non normal distribution (albuminuria and triglycerides) were presented as median (range). Categorical data were presented as absolute numbers and percentages. 
Table 1 - Clinical and laboratory characteristics of patients grouped according to the stages of diabetic retinopathy

\begin{tabular}{|c|c|c|c|c|}
\hline & & Diabetic Retinopathy & & \\
\hline & $\begin{array}{c}\text { Absent } \\
N=243\end{array}$ & $\begin{array}{c}\text { Mild/moderate } \\
\text { NPDR } \\
\mathrm{N}=84\end{array}$ & $\begin{array}{l}\text { Advanced DR } \\
\mathrm{N}=110\end{array}$ & $\mathbf{P}$ \\
\hline Age (years) & $25.0 \pm 7.7$ & $28.8 \pm 7.3$ & $32.5 \pm 5.8$ & $<0.001^{*}$ \\
\hline Age at diagnosis of DM (years) & $12.0 \pm 7.3$ & $14.0 \pm 5.5$ & $14.7 \pm 7.8$ & 0.146 \\
\hline DM duration (years) & $13.2 \pm 7.2$ & $15.8 \pm 6.0$ & $17.7 \pm 8.1$ & $<0.007^{* *}$ \\
\hline Male gender - $\mathrm{n}(\%)$ & $129(53.1)$ & $46(54.8)$ & $45(40.9)$ & 0.070 \\
\hline White - n (\%) & $201(82.7)$ & $63(75.0)$ & $96(87.3)$ & 0.081 \\
\hline Smoking habit n - (\%) & $41(16.9)$ & $20(23.8)$ & $40(36.4)$ & $<0.001$ \\
\hline Body mass index (kg/m2) & $23.0 \pm 5.0$ & $23.7 \pm 4.8$ & $23.3 \pm 6.0$ & 0.741 \\
\hline Waist circumference (cm) & & & & \\
\hline Male & $83.2 \pm 8.7$ & $84.9 \pm 9.5$ & $83.9 \pm 8.6$ & 0.770 \\
\hline Female & $81.3 \pm 9.5$ & $79.3 \pm 7.9$ & $84.1 \pm 8.9$ & 0.332 \\
\hline Systolic blood pressure (mm Hg) & $116.3 \pm 13.7$ & $125.4 \pm 17.6$ & $134.3 \pm 24.0$ & $<0.001^{*}$ \\
\hline Diastolic blood pressure (mm Hg) & $75.2 \pm 9.9$ & $79.1 \pm 10.7$ & $83.9 \pm 15.2$ & $<0.001^{*}$ \\
\hline Arterial hypertension - $\mathrm{n}(\%)$ & 21.20 & 38.36 & 56.10 & $<0.001$ \\
\hline Fasting plasma glucose (mg/dl) & $178.7 \pm 102.2$ & $189.5 \pm 118.8$ & $170.8 \pm 100.2$ & 0.522 \\
\hline $\mathrm{A} 1 \mathrm{C}$ test $(\%)$ & $8.90 \pm 5.26$ & $9.45 \pm 2.39$ & $8.84 \pm 1.98$ & 0.561 \\
\hline Total cholesterol (mg/dl) & $171.1 \pm 39.7$ & $181.2 \pm 49.6$ & $190.9 \pm 45.1$ & $0.002^{* *}$ \\
\hline HDL cholesterol (mg/dl) & $56.3 \pm 16.19$ & $56.3 \pm 15.9$ & $58.6 \pm 18.9$ & 0.590 \\
\hline LDL cholesterol (mg/dl) & $96.4 \pm 29.4$ & $104.9 \pm 39.6$ & $107.1 \pm 42.7$ & 0.060 \\
\hline Triglycerides (mg/dl) & $68(22-900)$ & $84(31-534)$ & $97(33-507)$ & $<0.001$ \\
\hline Serum creatinine (mg/dl) & $1.07 \pm 1.09$ & $1.28 \pm 1.34$ & $2.23 \pm 2.33$ & $<0.001$ \\
\hline Estimated GFR (ml/min/1.73 m2) & $109.0 \pm 34.11$ & $92.5 \pm 37.00$ & $66.4 \pm 34.5$ & $<0.001^{*}$ \\
\hline Urinary albumin excretion (mg/l) & $7.64(0.1-903)$ & $8.25(0.1-7110)$ & $72.67(0.1-9477)$ & $<0.001$ \\
\hline Normo/Micro-/Macro-ESRD (\%) & $78.97 / 14.87 / 6.14$ & $65.33 / 21.33 / 13.34$ & $25.33 / 28.0 / 46.67$ & $<0.001$ \\
\hline
\end{tabular}

Data expressed as mean ( \pm standard deviation), median [range] or number of cases (\%).

$\mathrm{NPDR}=$ non proliferative diabetic retinopathy

* absent DR vs. NPDR and advanced DR, ** absent DR vs. advanced DR Advanced DR vs. absent and NPDR. Current and former smokers

\section{RESULTS}

\section{Sample description}

A total of 437 patients were evaluated $(50.3 \%$ males, $82.4 \%$ whites). Mean age at ophthalmologic examination was $26.8 \pm$ 7.8 years and at diagnosis of DM was $12.9 \pm 7.1$ years. Duration of DM was $14.4 \pm 7.3$ years. Overall prevalence of any DR was $44.4 \%(n=194)$. Sixty-six patients $(15.1 \%)$ had mild NPDR, 18 patients $(4.2 \%)$ moderate NPDR, $13(3.0 \%)$ patients severe NPDR, and 97 patients (22.2\%) were diagnosed with PDR.

Patients with mild and moderate NDPR were grouped as mild/ moderate $(n=84)$, and patients with severe NPDR and PDR were grouped as advanced DR $(n=110)$.

\section{Demographic, anthropometric and smoking habit data}

Clinical and laboratory features of type 1 DM patients grouped according to the degree of DR are shown in Table 1.

Patients with absent DR had a shorter duration of DM and were younger than the patients with mild/moderate NPDR and advanced DR. Duration of DM was not different between patients with mild/moderate NPDR and advanced DR. Onset of DM occurred earlier for patients without DR when compared to patients with mild/moderate NPDR and advanced DR. Gender proportion, ethnic group and anthropometric indices did not differ among groups. Neither general obesity (BMI) nor central obesity (waist circumference) was linked to DR.
Current or past smoking history was associated with DR $(P<0.001)$. There was a progressive increase in the frequency of smokers/former smokers among those with absent DR, mild/ moderate DR and advanced DR ( $P$ for trend $<0.001$ ).

Blood pressure and glycemic control

Patients with mild/moderate NPDR and advanced DR had higher SBP than patients without DR (Table 1). The DBP levels were higher in the group with advanced DR than in patients without DR, but DBP was not different between those without DR and with mild/moderate NPDR. There was a progressive increase in the prevalence of arterial hypertension from those without DR to mild/moderate NPDR and advanced DR $(21.0 \%$ vs. 38.1 vs. $56.4 \%$ : $P<0.001$ ).

There was no difference in FPG values among the three groups ( $178.7 \pm 102.2$ vs. $189.5 \pm 118.8$ vs. $170.8 \pm 100.2$ $\mathrm{mg} / \mathrm{dl}, \mathrm{P}=0.520)$. The $\mathrm{A} 1 \mathrm{C}$ test was higher among those with $\mathrm{mild} /$ moderate NPDR and advanced DR when compared to those without DR.

Figure 1 shows the frequency of advanced DR according to SBP and A1C test quartiles. Prevalence of advanced DR was $8.2 \%$ in patients in the lower A1C test and SBP quartiles. Even in patients with the best metabolic control (A1C test $<7.2 \%$ ), prevalence of advanced DR increased with the increase of blood pressure quartiles, reaching $28 \%$ in those of the upper SBP quartile (>130 mm Hg). The same pattern was observed for the A1C quartiles in those with low SBP $(<110 \mathrm{~mm} \mathrm{Hg})$. Those in the 


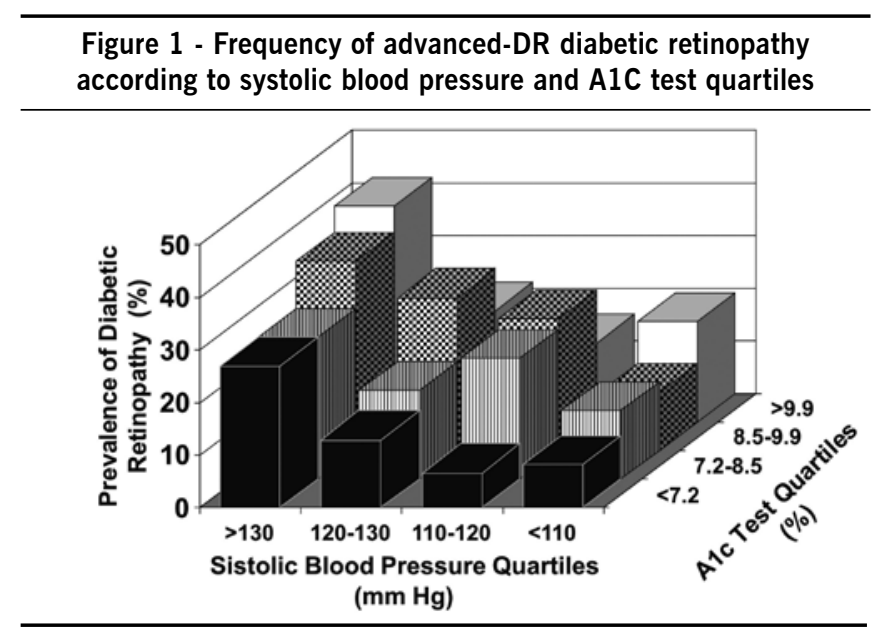

upper quartiles for A1C test and SBP had the highest prevalence of severe DR (41\%).

\section{Lipid profile}

Patients with advanced DR had higher values of total cholesterol, LDL cholesterol and triglycerides than patients without DR. There were no differences in the levels of HDL cholesterol values among groups.

\section{Renal function}

Patients with advanced-DR had higher serum creatinine values than patients with mild/moderate NPDR and without DR. Estimated GFR was also lower among patients with advanced DR than among those with mild/moderate NPDR or without DR.

There was a progressive increase in UAE according to the degree of retinal involvement, lower among those patients without DR and higher among those with advanced DR. To establish an index of magnitude, subjects were divided according to the UAE into normo, micro or macroalbuminurics. Subjects with ESRD were included in the macroalbuminuric group. Microalbuminuria increases the chance of advanced DR by 4.8 times $(95 \% \mathrm{Cl} 2.5-9.4, \mathrm{P}<0.001)$, but not the mild/moderate forms (OR $1.75,95 \% \mathrm{Cl} 0.9-3.5, \mathrm{P}=0.320$ ). Macroalbuminuria was associated with both, mild/moderate NPDR (OR 2.6, 95\% Cl 1.1-6.3, P =0.020) and advanced DR (OR 23.3, 95\% Cl 11.0 - 50. 1, $\mathrm{P}<0.001$ ).

\section{Macular edema}

In the subset of 223 patients in whom the presence of CSME was evaluated, 21 patients (9.4\%) presented CSME, and this frequency increased with the severity of DR: $16.4 \%$ in advanced DR, $9.6 \%$ in mild/moderate NPDR, and $4.7 \%$ in the group without DR ( $P=0.020)$. Current smoking was also associated with CSME (OR 3.19, 95\% Cl 1.24-8.2, $\mathrm{P}=0.012)$. There was a progressive increase in the frequency of CSME according to renal status: normo $5.4 \%$, micro $11.4 \%$, and macroalbuminuria $22.2 \%$ ( $P$ for trend 0.005 ). CSME was not associated with gender, ethnicity, blood pressure levels, lipid profile, serum creatinine or metabolic control.

\section{Multivariate analysis}

\section{Mild/moderate non proliferative diabetic retinopathy}

Mild/moderate NPDR was associated with most variables, except for total cholesterol, and smoking. SBP, A1C test, microalbuminuria (log transformed), DM duration, total cholesterol and smoking (current or past) were included in the initial multivariate logistic regression model. For each increase in one year of DM duration, in one $\mathrm{mmHg}$ in SBP or in one point in $\mathrm{A} 1 \mathrm{C}$ test, there was an increased chance of presenting mild/moderate NPDR of $6 \%, 2 \%$ and $2 \%(P<0.005)$, respectively.

Other models were constructed substituting SBP for DBP or arterial hypertension, or substituting total cholesterol for triglycerides (log transformed), or degree of albuminuria for stages of diabetic nephropathy (norn, micro or macroalbuminuria) or serum creatinine. The inclusion of arterial hypertension instead of SBP showed an OR of $3.12(95 \% \mathrm{Cl} 1.06-9.40)$. Neither DBP nor triglycerides were associated with mild/moderate NPDR. When microalbuminuria was replaced by serum creatinine, the OR for mild/moderate NPDR was 1.76 (95\% Cl 1.03-3.48).

\section{Advanced diabetic retinopathy}

Advanced DR was associated to all variables with the exception of total cholesterol and $\mathrm{A} 1 \mathrm{C}$ test. Each increase in one year of DM duration or in one $\mathrm{mmHg}$ in SBP was associated with an increase in the odds of advanced DR of $4 \%(95 \% \mathrm{Cl} 1.3-7.8, \mathrm{P}$ $<0.05)$. Smoking increased chances for advanced DR by 2.75 times (OR 95\% Cl 1.15-6.60). Hypertension was associated with an OR of 2.48 (95\% Cl 1.13-5.40) for advanced DR. Presence of diabetic nephropathy (DN) (micro- or macroalbuminuria) was associated with an OR of 8.53 (95\% Cl 3.81-18.05). When serum creatinine was used in the model instead of microalbuminuria it was also associated with advanced DR (OR 2.64 - 95\% Cl 1.40-5.01).

The five major independent risk factors for advanced DR were dichotomized into present or absent (arterial hypertension, DN and smoking) or above or below the median value ( $\mathrm{A} 1 \mathrm{C}$ test $8.7 \%$ and DM duration - 17 years). Forty-two of the patients $(9.6 \%)$ had no risk factors, 131 patients (30\%) had one, 139 (31.8\%) two, 49 (11.4\%) three, 50 (11.4\%) four, and only 7 patients $(1.6 \%)$ had all five risk factors. The prevalence of advanced DR increased with the number of risk factors (Figure 2 ). However, even in the presence of four or five risk factors, about $40 \%$ of the subjects were free of the most severe degree of DR (proliferative form).

\section{Discussion}

In this study, DR was present in a high percentage of this sample of type $1 \mathrm{DM}$ patients and it was associated with the main traditional risk factors, namely glycemic control, blood pressure and DM duration. On the other hand, glycemic control was not associated with advanced DR in multivariate analyses. This may suggest that for more severe forms of DR, glycemic control does not play a major role as observed for systolic blood pressure. An alternative explanation is that absence of association could reflect improvement of glycemic control that results from medical advice, once diagnosis of this severe microvascular chronic 


\section{Figure 2 - Prevalence of advanced diabetic retinopathy and number of risk factors present (hypertension, diabetic nephropathy, smoking habit, A1C test $>8.7 \%$ and diabetes mellitus duration $>17$ years)}

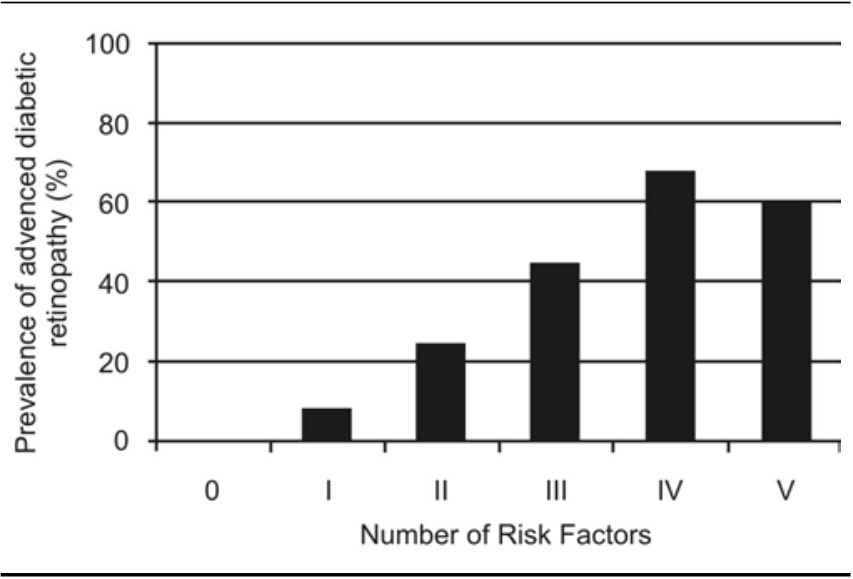

complication is established. However, the cross-sectional design adopted precludes confirmation of this hypothesis.

Another aspect that must be highlighted is the association of smoking with any degree of DR found in this study. Smoking habits and DR are controversially related ${ }^{11}$ and no association has been described by some authors ${ }^{21}$. In patients with type 2 DM we, as others, had previously described a protective association of smoking and DR 16, 22 .

Overt DN is well known to be associated with DR ${ }^{23}$. Also, association of incipient DN and DR was previously described in type $1 \mathrm{DM}$ patients ${ }^{24}$. In the present study, microalbuminuria was associated only with more severe forms of DN. We have shown a similar association in patients with type $2 \mathrm{DM}^{16}$. Concordance of DN and DR could be due to common risk factors or could be a marker of general vascular damage, leading to leakage of protein from retinal vessels ${ }^{7}$.

Association of total cholesterol levels with DR had been clearly demonstrated, especially in type 2 DM patients ${ }^{25,26}$. However, this was not observed in the present study for any DR. This could be explained by low mean levels of total cholesterol ( $<200 \mathrm{mg}$ / $\mathrm{dl}$ ) of our patients studied, probably related to their young age. Finally, unmarked influence of $A 1 C$ test levels in patients with severe forms of DR could reflect the major role of genetic factors in advanced DR stages of diabetic eye disease. This aspect is reinforced by a high magnitude of OR for almost all DR risk factors evaluated in this study.

Diabetic maculopathy is the most common cause of visual impairment in diabetic patients. ${ }^{27}$ CSME must be considered for treatment with laser photocoagulation irrespective of the level of visual acuity or DR stage, because treatment reduces the risk of visual loss by $50 \%{ }^{27}$. Risk factors for CSME are not conclusively established. A positive relation of CSME with DN, severity of DR and smoking history was found in our patients. Association of albuminuria and CSME is an interesting finding from a clinical point of view. Probably, presence of even early DN stages should alert the physician to the need of an ophthalmologic evaluation.
High values of LDL cholesterol and total cholesterol-HDL cholesterol ratio have been suggested to increase by two and fourfold the risk of CSME, respectively ${ }^{28}$. In type $1 \mathrm{DM}$ patients, old age at diagnosis of DM, male gender and higher A1C test levels significantly increase the risk of clinically significant macular edema $^{29}$. We did not find an association between demographic data, blood pressure, lipid profile or metabolic control indices and CSME. This could be due to the low power to detect these associations since there were only 22 patients with CSME. This would also preclude performing a multivariate analysis to identify the independence of the associations found.

\section{Conclusion}

In conclusion, prevalence of $44.4 \%$ of any DR in type 1 DM patients attending a general hospital shows that this condition continues to be a major public health problem despite current knowledge about advanced DR. Furthermore, prevalence of $24 \%$ of advanced DR stages is a warning sign. Those with a long DM duration, positive smoking, elevated blood pressure, poor metabolic control and albuminuria are at highest risk of presenting advanced DR forms. Finally, CSME should be suspected in presence of smoking or any degree of DN.

\section{ACKNOWLEDGEMENTS}

Grant Support: Research supported by grants from Conselho Nacional de Desenvolvimento Científico e Tecnológico (CNPq) and Fundo de Incentivo a Pesquisa e Eventos (FIPE)- Hospital de Clínicas de Porto Alegre. LHC was the recipient of a postdoctoral (ProDoc) grant from Fundação de Coordenação de Aperfeiçoamento de Pessoal de Ensino Superior (Fundação CAPES) and MP was the recipient of a posdoctoral grant from CNPq.

\section{Conflict of interest: none}

\section{Resumo}

Prevalência de retinopatia diabética em pacientes com Diabetes MELLITUS TIPO 1

OBJETIVos. Determinar a prevalência de RD e seus fatores de risco em pacientes com DM tipo 1 atendidos em um hospital geral.

Métodos. Foi realizado um estudo transversal com 437 pacientes (50,3\% homens, $82,4 \%$ brancos). RD foi agrupada em: 1) ausente; 2) não proliferativa leve e moderada (RDNP leve/moderada); 3) não prolifetiva grave e $R D$ proliferativa ( $R D$ avançada). Edema de mácula clinicamente significativo (EMCS) também foi registrado.

Resultados. Qualquer grau de RD esteve presente em $44,4 \%$ dos pacientes. Na análise multivariada, duração do $D M$, pressão arterial sistólica e teste $A 1 C$ foram associados com a $R D$ leve/moderada $(P<0,005)$. $R D$ avançada foi associada com duração do DM, pressão arterial sistólica (PAS), fumo [razão de chances (RC) 2,75, IC 95\% 1,15-6,60] e micro- ou macroalbuminúria (RC 8,53, Cl 95\% 3,81-18,05). EMCS esteve presente em 21 (9,4\%) dos pacientes associado ao fumo, aumentando com a gravidade da RD (16,4\% RD avançada; 9,6\% RD leve/modera, e 4,7\% no grupo sem $R D$; $P=0,020)$. 
Conclusão. Pacientes com DM tipo 1 vistos em um hospital geral têm uma alta prevalência de RD, a qual foi associada aos fatores de risco tradicionais e fumo. [Rev Assoc Med Bras 2009; 55(3): 268-73]

UnITERmos: Diabetes mellitus tipo 1. Retinopatia diabética. Fatores de risco.

\section{References}

1. Fong DS, Aiello LP, Ferris FL, 3rd, Klein R. Diabetic retinopathy. Diabetes Care. 2004; 27:2540-53.

2. Roy MS, Klein R, OColmain BJ, Klein BE, Moss SE, Kempen JH. The prevalence of diabetic retinopathy among adult type 1 diabetic persons in the United States. Arch Ophthalmol. 2004; 122:546-51.

3. Bryden KS, Dunger DB, Mayou RA, Peveler RC, Neil HA. Poor prognosis of young adults with type 1 diabetes: a longitudinal study. Diabetes Care. 2003;26:1052-7.

4. Lovestam-Adrian M, Agardh CD, Torffvit O, Agardh E. Diabetic retinopathy, visual acuity, and medical risk indicators: a continuous 10-year follow-up study in Type 1 diabetic patients under routine care. J Diabetes Complications. 2001;15:287-294.

5. Krolewski AS, Warram JH, Rand LI, Christlieb AR, Busick EJ, Kahn CR. Risk of proliferative diabetic retinopathy in juvenile-onset type I diabetes: a 40-yr follow-up study. Diabetes Care. 1986; 9:443-52.

6. Agardh E, Torffvit O, Agardh CD. The prevalence of retinopathy and associated medical risk factors in type I (insulin-dependent) diabetes mellitus. J Intern Med. 1989;226:47-52

7. Ciulla TA, Amador AG, Zinman B. Diabetic retinopathy and diabetic macular edema: pathophysiology, screening, and novel therapies. Diabetes Care. 2003;26:2653-64.

8. Van Leiden HA, Dekker JM, Moll AC, Nijpels G, Heine RJ, Bouter LM, et al. Risk factors for incident retinopathy in a diabetic and nondiabetic population: the Hoorn study. Arch Ophthalmol. 2003;121:245-51.

9. Klein R, Klein BE, Moss SE, Davis MD, DeMets DL. Glycosylated hemoglobin predicts the incidence and progression of diabetic retinopathy. JAMA. 1988;260:2864-71.

10. Janka HU, Warram JH, Rand LI, Krolewski AS. Risk factors for progression of background retinopathy in long-standing IDDM. Diabetes. 1989. 38:460-4

11. Esteves J, Laranjeira AF, Roggia MF, Dalpizol M, Scocco C, Kramer CK, et al. [Diabetic retinopathy risk factors]. Arq Bras Endocrinol Metabol. 2008; 52:431-441.

12. Zhang L, Krzentowski G, Albert A, Lefebvre PJ. Risk of developing retinopathy in Diabetes Control and Complications Trial type 1 diabetic patients with good or poor metabolic control. Diabetes Care. 2001; 24:1275-1279.

13. Diabetes Mellitus: Report of a WHO Study Group. Geneva: World Health Org; 1985.

14. Wilkinson CP, Ferris FL, 3rd, Klein RE, Lee PP, Agardh CD, Davis M, et al. Proposed international clinical diabetic retinopathy and diabetic macular edema disease severity scales. Ophthalmology. 2003; 110:1677-1682.
15. The Diabetic Retinopathy Study Research Group: a modification of the Arlie House classifiation of Diabetic retinopathy (DRS report no. 7). Invest Ophthalmol Vis Sci. 1981; 21:210-226.

16. Boelter MC, Azevedo MJ, Gross JL, Lavinsky J. Fatores de risco para retinopatia diabética. Arq Bras Oftalmol. 2003;66:239-47.

17. Photocoagulation for diabetic macular edema. Early Treatment Diabetic Retinopathy Study report number 1. Early Treatment Diabetic Retinopathy Study research group. Arch Ophthalmol. 1985;103:1796-806.

18. Grading diabetic retinopathy from stereoscopic color fundus photographs--an extension of the modified Airlie House classification. ETDRS report number 10. Early Treatment Diabetic Retinopathy Study Research Group. Ophthalmology. 1991;98:786-806.

19. Gross JL, de Azevedo MJ, Silveiro SP, Canani LH, Caramori ML, Zelmanovitz T. Diabetic nephropathy: diagnosis, prevention, and treatment. Diabetes Care. 2005;28:164-76.

20. Levey AS, Bosch JP, Lewis JB, Greene T, Rogers N, Roth D. A more accurate method to estimate glomerular filtration rate from serum creatinine: a new prediction equation. Modification of Diet in Renal Disease Study Group. Ann Intern Med. 1999;130:461-70.

21. Cantoni A CM, Congeti I, Carrerasi G, Castell C, Tresserras R. Type 1 Diabetes Mellitus in Catalonia: Chronic complications and Metabolic control ten years after onset. Med Sci Monit. 2005;10:185-90.

22. Stratton IM, Kohner EM, Aldington SJ, Turner RC, Holman RR, Manley SE, et al. UKPDS 50: risk factors for incidence and progression of retinopathy in Type II diabetes over 6 years from diagnosis. Diabetologia. 2001;44:156-63.

23. Klein R, Moss SE, Klein BE. Is gross proteinuria a risk factor for the incidence of proliferative diabetic retinopathy? Ophthalmology. 1993;100:1140-6.

24. Parving $\mathrm{HH}$, Hommel E, Mathiesen E, Skott P, Edsberg B, Bahnsen M, et al. Prevalence of microalbuminuria, arterial hypertension, retinopathy and neuropathy in patients with insulin dependent diabetes. Br Med J (Clin Res Ed). 1988;296:156-60.

25. Klein BE, Moss SE, Klein R, Surawicz TS. The Wisconsin Epidemiologic Study of Diabetic Retinopathy. XIII. Relationship of serum cholesterol to retinopathy and hard exudate. Ophthalmology. 1991;98:1261-5.

26. Chew EY, Klein ML, Ferris FL, 3rd, Remaley NA, Murphy RP, Chantry K, et al. Association of elevated serum lipid levels with retinal hard exudate in diabetic retinopathy. Early Treatment Diabetic Retinopathy Study (ETDRS) Report 22. Arch Ophthalmol. 1996;114:1079-84.

27. Kanski JJ. Diabetic retinopathy--a preventable cause of blindness. Practitioner. 1985;229:343-8.

28. Miljanovic B, Glynn RJ, Nathan DM, Manson JE, Schaumberg DA. A prospective study of serum lipids and risk of diabetic macular edema in type 1 diabetes. Diabetes. 2004;53:2883-92.

29. Vitale S, Maguire MG, Murphy RP, Hiner CJ, Rourke L, Sackett C, et al. Clinically significant macular edema in type I diabetes. Incidence and risk factors. Ophthalmology. 1995;102:1170-6.

Artigo recebido: 13/06/08 Aceito para publicação: 13/09/08 